\title{
Stimulatory Effects of Ginsan on the Proliferation and Viability of Mouse Spleen Cells
}

\author{
Eun-Ju Ko, and Hong-Gu Joo \\ Laboratory of Veterinary Pharmacology, College of Veterinary Medicine, Jeju National University, Jeju 690-756, Korea
}

\begin{abstract}
Ginsan is an acidic polysaccharide purified from Panax ginseng, a famous oriental herb. Although a variety of biological activities of ginsan have been studied, the effects of ginsan on spleen cells are not fully elucidated. We investigated the effect of ginsan on the viability and proliferation of spleen cells. Using Cell Counting Kit- $8^{\circledR}$ solution and trypan blue solution, we found that ginsan significantly enhanced viability and proliferation. Multiple clusters, indicating proliferation, were observed in ginsan-treated spleen cells and, carboxyfluorescein succinimidyl ester and surface marker staining assay revealed that ginsan promoted proliferation from $\mathrm{CD}^{+}{ }^{+} \mathrm{B}$ cells rather than $\mathrm{CD}^{+}$or $^{\mathrm{CD}} 8^{+}$ $T$ cells. In addition, ginsan decreased the percentage of late apoptotic cells. Ginsan increased the surface expression of CD25 and CD69 as well as production of interleukin-2 from spleen cells, suggesting increased activation. Taken together, these results demonstrate that ginsan increases the viability and proliferation of spleen cells via multiple mechanisms, valuable information for broadening the use of ginsan in clinical and research settings.
\end{abstract}

Key Words: B lymphocytes, Ginsan, Stimulation, Proliferation, Spleen cells

\section{INTRODUCTION}

Ginsan is a polysaccharide purified from Panax ginseng, a famous natural herb used in Asian medicine. Ginsan has multiple biological activities, including a protective effect against liver injury [1], radioprotective activity in bone marrow cells [2] and the small intestine, chemoprotective and adjuvant effects in tumors [3], and anti-inflammatory effects in sepsis [4]. We recently demonstrated that ginsan also strongly stimulates dendritic cells, the most potent antigen-presenting cells in the immune system [5].

The spleen is a critical immune organ that contains lymphocytes and other immune cells; it serves as the major site for recognition of blood-borne antigens by the immune system and is involved in the removal of old or damaged cells in blood. The effect of ginsan on lymphocytes and the spleen is not well understood. Ginsan synergizes with recombinant interleukin (IL)-2 in generating LAK cells [6] and restores the mRNA level of interferon (IFN)-gamma when cells are suppressed by gamma irradiation [7]. To further elucidate the effects of ginsan on spleen cells, we investigated which lymphocyte subset responds to ginsan and whether ginsan has cytoprotective effects on spleen cells.

Received April 12, 2010, Revised May 16, 2010,

Accepted May 19, 2010

Corresponding to: Hong-Gu Joo, Laboratory of Veterinary Pharmacology, College of Veterinary Medicine, Jeju National University, 66, Jejudaehak-no, Ara-1-dong, Jeju 690-756, Korea. (Tel) 82-64-754-3379, (Fax) 82-64-756-3354, (E-mail) jooh@jejunu.ac.kr

\section{METHODS}

\section{Animals and reagents}

Balb/c mice were purchased from ORIENT BIO (Republic of Korea) and maintained in our animal facility. 7- to 12 -week old, female mice were used for all experiments. Ginsan was kindly provided by Korea Institute of Radiological and Medical Sciences (Republic of Korea) and dissolved in sterile phosphate-buffered saline.

\section{Preparation and culture of mouse spleen cells}

Spleen cells were purified from Balb/c mice [8]. Briefly, spleens were disrupted with mechanical force and treated with hypotonic lysis buffer to remove red blood cells. After incubation in T75 culture flask for $1 \mathrm{hr}$, the cells were passed through $40 \mu \mathrm{m}$ cell strainer to get single cells. Spleen cells were cultured in a lymphocyte culture medium, RPMI 1640 containing 10\% fetal bovine serum, $2 \mathrm{mM} \mathrm{L-glu-}$ tamine, $0.1 \mathrm{mM}$ non-essential amino acids, $1 \mathrm{mM}$ sodium pyruvate, $100 \mathrm{IU} / \mathrm{ml}$ penicillin/streptomycin, $50 \mu \mathrm{M} 2$-mercaptoethanol.

\section{Measurement of the viability and proliferation of spleen cells}

The spleen cells were seeded at a concentration of $2 \times 10^{5}$

ABBREVIATIONS: IL, interleukin; IFN, interferon; PE, phycoerythrin; FITC, fluorescein isothiocyanate; PI, propidium iodide; CFSE, carboxyfluorescein diacetate succinimidyl ester; ELISA, Enzyme-linked immunosorbent assay. 
cells/200 $\mu \mathrm{l} /$ well in 96 -well culture plates for a cell viability/proliferation assay, using Cell Counting Kit- $8^{\mathbb{R}}$ solution (Dojindo, Gaithersburg, MD). Briefly, the cultured wells were treated with $10 \mu \mathrm{l} /$ well of Cell Counting Kit- ${ }^{(\mathbb{R}}$ solution for last $4 \mathrm{hr}$ and the optical density of wells was measured at $450 \mathrm{~nm}$ using a microplate reader (Molecular devices, Sunnyvale, CA). For measuring cell viability, the treated spleen cells in 96-well culture plates were stained with a trypan blue solution (Invitrogen, Carlsbad, CA) and the viable and dead cells counted. The pictures of cultured cells were taken by digital camera (Cannon Inc., Tokyo, Japan) connected to inverted microscope (Olympus Co., Tokyo, Japan).

\section{Flow cytometric analysis}

The spleen cells were cultured at a concentration of $5 \times 10^{6}$ cells $/ 5 \mathrm{ml} /$ well in 6 -well culture plates in the absence or presence of ginsan for 3 days for flow cytometric analysis. The staining of cells was processed as established in our laboratory $[2,9]$. Spleen cells were treated with biotin-labeled anti-CD4, anti-CD8, anti-CD19, anti-CD25 antibody and then streptavidin-phycoerythrin (PE), or PE-labeled anti-CD69 antibody (all from BD Biosciences, San Jose, CA). For measuring the cell death, both apoptosis and necrosis, spleen cells were stained with annexin V-fluorescein isothiocyanate (FITC)/ propidium iodide (PI) kit (Biosource International) according to the manufacturer's instruction. To check the membrane potential of mitochondria [10],

A

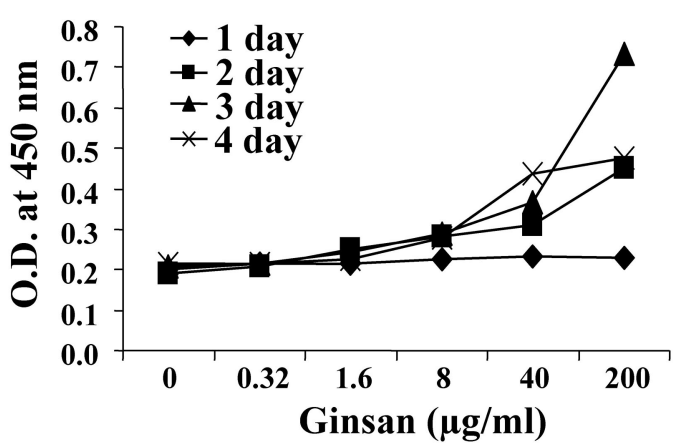

B

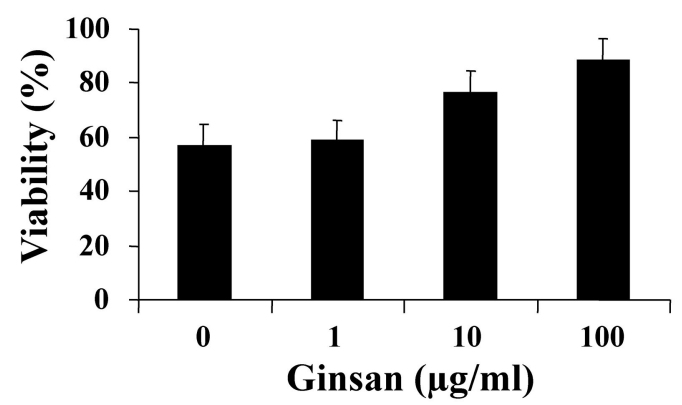

Fig. 1. Effect of ginsan on the proliferation/viability of spleen cells. The spleen cells were cultured at a concentration of $2 \times 10^{5}$ cells/ $200 \mu \mathrm{l} /$ well in 96-well culture plates. (A) Proliferation assay using Cell Counting Kit- $8^{\mathbb{R}}$ solution, in which spleen cells were treated with $0 \sim 200 \mu \mathrm{g} / \mathrm{ml}$ ginsan for 4 days. (B) Trypan blue exclusion test, in which spleen cells were treated with $0 \sim 100 \mu \mathrm{g} / \mathrm{ml}$ ginsan for 3 days. Data are mean \pm SD from three or four individual wells. spleen cells were incubated with $10 \mu \mathrm{g} / \mathrm{ml}$ rhodamine 123 (Sigma) for $30 \mathrm{~min}$ at room temperature. All stained cells were analyzed by FACSCalibur ${ }^{\mathrm{TM}}$ and CellQuest ${ }^{\mathrm{TM}}$ (Beckton Dickinson, Franklin Lakes, NJ). For measuring the proliferation of specific cell subsets, the spleen cells were stained with $5 \mu \mathrm{M}$ carboxyfluorescein diacetate succinimidyl ester (CFSE) for 10 min and then cultured in 96-well culture plates with or without ginsan.

\section{Enzyme-linked immunosorbent assay (ELISA)}

Spleen cells were cultured as described in the viability/ proliferation assay. After 3 day culture, the supernatants were harvested and used for ELISA. The amounts of IL-2 and IL-4 in supernatants were determined by using CytoSet $^{\mathrm{TM}}$ kit (Biosource International) according to the manufacturer's instruction.

\section{Statistical analysis}

Data were presented as mean $\pm \mathrm{SD}$ and statistically analyzed by Tukey-Kramer multiple comparisons test. A p value of $<0.05$ was considered as significant.

\section{RESULTS}

\section{The effect of ginsan on the proliferation and viability} of spleen cells

To study the effect of ginsan on the proliferation and viability of spleen cells, we utilized CCK- 8 assay and a trypan blue exclusion test. The optical density of spleen cells treated with $0 \sim 200 \mu \mathrm{g} / \mathrm{ml}$ ginsan was measured for 4 days. Interestingly, ginsan promoted splenic cell proliferation at $8 \sim 200 \mu \mathrm{g} / \mathrm{ml}$ from day 2 through day 4 (Fig. $1 \mathrm{~A}$ ). To de-

A
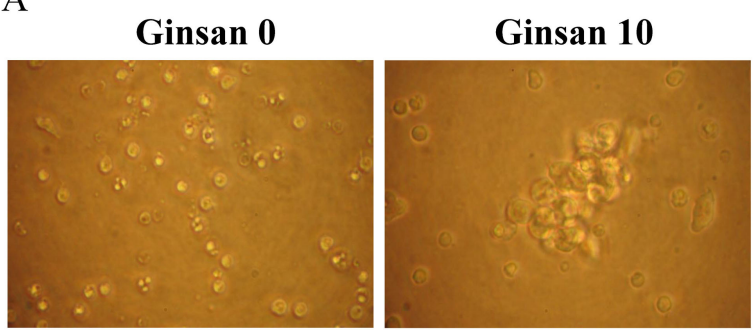

B

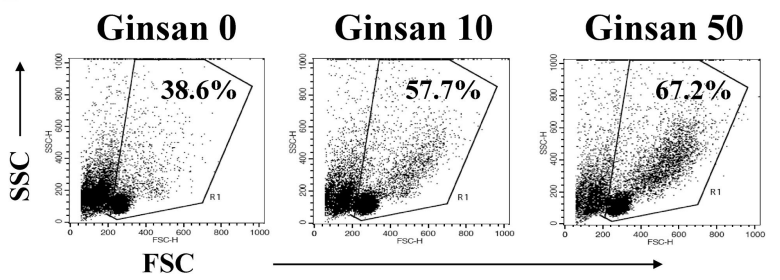

Fig. 2. Proliferating clusters in ginsan-treated spleen cells. Spleen cells were cultured as described in Fig. 1, and treated with medium alone, $10 \mu \mathrm{g} / \mathrm{ml}$ or $50 \mu \mathrm{g} / \mathrm{ml}$ ginsan for 3 days. (A) Cell morphology was observed using an inverted microscope and the image was obtained by a digital camera. (B) Cell size of the treated spleen cells was analyzed by flow cytometry. 
termine the effect of ginsan on the viability of spleen cells, we used trypan blue staining. The viability of spleen cells treated with ginsan was significantly greater than controls at concentrations of 10 and $100 \mu \mathrm{g} / \mathrm{ml}$ (Fig. 1B). Clusters of proliferating spleen cells treated with ginsan were visualized by an inverted microscope (Fig. 2A). Based on cell size analysis (Fig. 2B), ginsan profoundly increased the percentage of blasting cells located in a given region (R1). Thus, the results of proliferation and viability assays suggest that ginsan has some stimulatory effects on spleen cells. To further investigate which subset of spleen cells proliferate, we utilized CFSE to identify dividing cells after ginsan treatment for 3 days (where the CFSE intensity of proliferating cells gradually decreases upon repetitive divisions). CD $19^{+}$B lymphocytes selectively proliferated with ginsan treatment, whereas $\mathrm{CD} 4^{+}$and $\mathrm{CD} 8^{+} \mathrm{T}$ lymphocytes did not (Fig. 3).

\section{The protective effects of ginsan on spontaneous cell death of spleen cells}

Harvested spleen cells gradually enter a spontaneous cell death process due to the absence of the growth cytokines that in vivo provide survival and proliferating signals [11-13]. To investigate whether ginsan may protect spleen cells from spontaneous cell death in vitro, we stained cells with annexin V-FITC and PI to measure cellular apoptosis and necrosis. Indeed, as shown in Fig. 4, ginsan protected spleen cells from cell death, as illustrated by the increase of cell percentage in the lower left quadrant and the decrease of cell percentage in the upper right quadrant of the dot figure. To measure the action potentials of the mitochondrial membrane, the cells were stained with rhodamine 123 solution, because apoptotic and necrotic cells
Ginsan 0
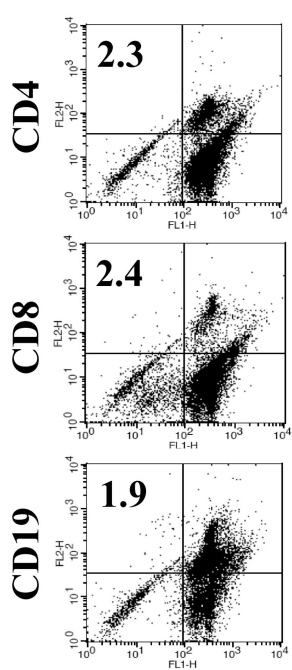

CFSE
Ginsan 10
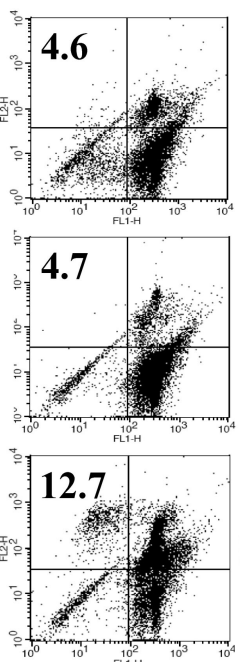

Ginsan 50
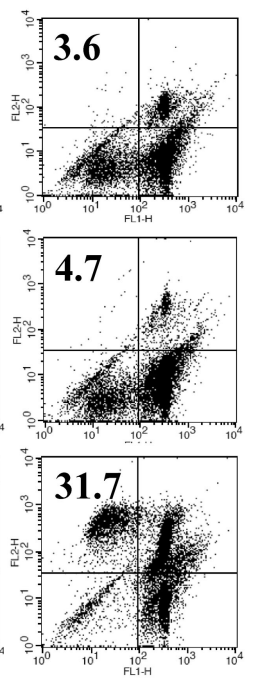

Fig. 3. Selective proliferation of $\mathrm{CD} 19^{+}$B lymphocytes by ginsan treatment. Spleen cells were stained with CFSE and cultured in 96 -well culture plates with medium alone or $10 \mu \mathrm{g} / \mathrm{ml}$ or $50 \mu \mathrm{g} / \mathrm{ml}$ ginsan for 2 days. After harvesting, the cells were labeled with surface marker-specific antibodies. The numbers indicate the percentage of proliferating cells of a specific subset. have lower action potentials than viable cells. The analysis indicated that ginsan increases the action potentials of the mitochondrial membrane of spleen cells (Fig. 4).

\section{Enhanced expression of activation markers on ginsan- treated spleen cells}

To determine the effect of ginsan on lymphocyte activation, we measured the surface expression levels of the activation markers CD25 and CD69 on spleen cells following treatment with ginsan. CD25 is an alpha chain of the IL-2 receptor that enhances the sensitivity of lymphocytes to IL-2, and CD69 is an early-activation marker for lymphocytes [14]. Treatment with $50 \mu \mathrm{g} / \mathrm{ml}$ ginsan increased the expression of both activation markers on spleen cells (Fig. 5).

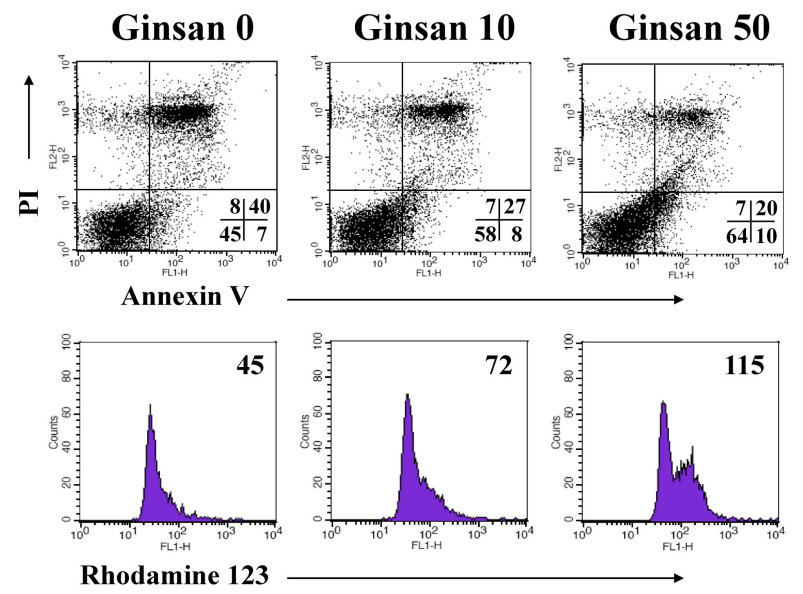

Fig. 4. Ginsan protects spleen cells against spontaneous cell death. Spleen cells were cultured at a concentration of $5 \times 10^{6}$ cells $/ 5$ $\mathrm{ml} /$ well in 6 -well culture plate. Following ginsan treatment, spleen cells were harvested and stained with annexin V-FITC/PI or rhodamine 123. The numbers indicate cell percentage and mean fluorescence intensity, respectively.
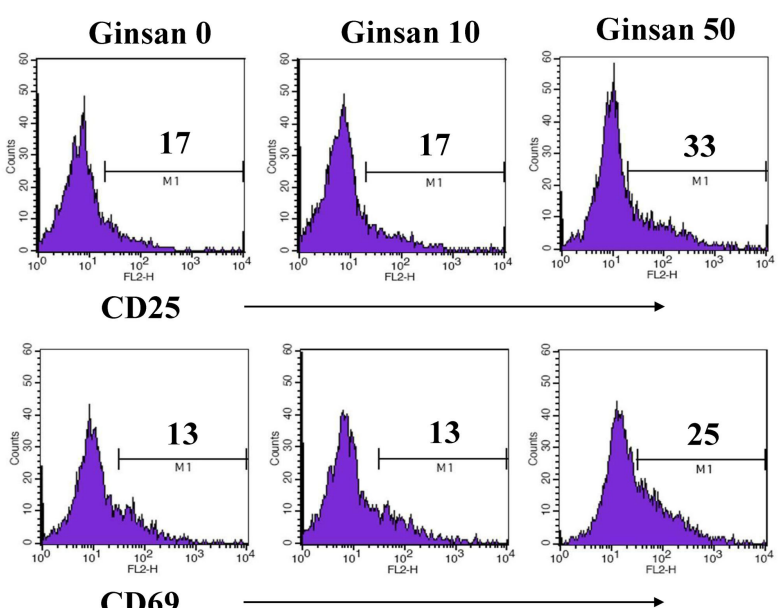

Fig. 5. Enhanced expression of activation markers on spleen cells treated with ginsan. Spleen cells were cultured and treated as described in Fig. 4. The number of histograms indicates the percentage of highly expressed cells. 
Flow cytometry analysis demonstrated that ginsan increases some activation markers on spleen cells, which may sensitize cells to growth cytokines such as IL-2.

\section{Ginsan-activated spleen cells respond to $I L-2$}

To generate an immune response, it is critical to induce the proliferation of lymphocytes, including clonal expansion

A

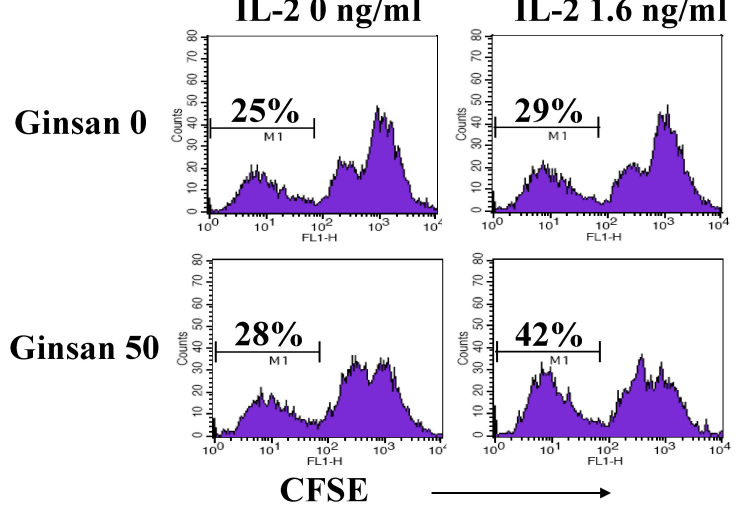

B

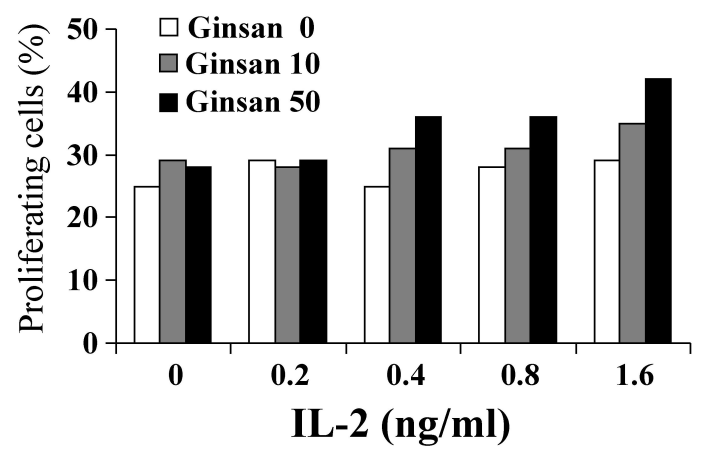

$\mathrm{C}$

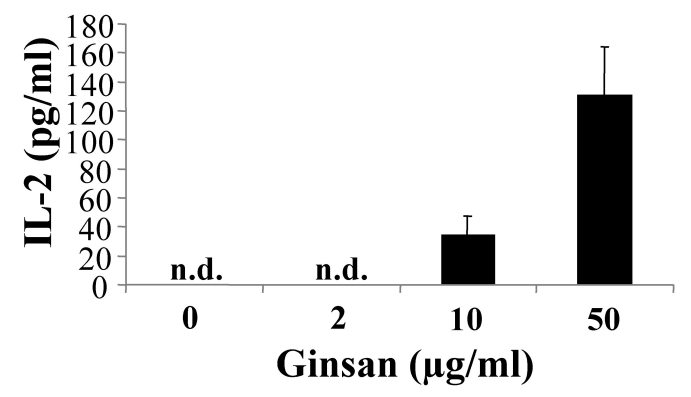

Fig. 6. IL-2 responsiveness of ginsan-activated spleen cells. (A, B) Spleen cells were cultured as described Fig. 4 and treated with ginsan for 2 days. The harvested cells were stained with CFSE and incubated in 24-well culture plates in the presence of IL-2 for 5 days. The percentage of low-intensity CFSE signals indicates proliferating cells. (C) Spleen cells were cultured as described in Fig. 1 and treated with the indicated concentrations of ginsan. After 3 days of treatment, the supernatants were collected and IL-2 and IL- 4 were quantified. Data are mean \pm SD from four individual wells.
$[15,16]$. IL-2 is a major cytokine for lymphocyte expansion. Therefore, to investigate whether ginsan-activated spleen cells may respond to IL-2, we treated spleen cells with ginsan for 2 days and then cultured the ginsan-activated cells in the presence of IL-2. Indeed, ginsan-activated spleen cells proliferated in response to IL-2 (Fig. 6A, B). To determine if ginsan induces the production of cytokines required for lymphocyte growth, IL-2 and IL- 4 were measured from the supernatants of spleen cells treated with ginsan. IL-2 production increased in a concentration-dependent manner (Fig. 6C), however, the same supernatants did not contain detectable amounts of IL-4 (data not shown). These results suggest that ginsan may sensitize spleen cells to IL-2, in an autocrine or paracrine manner.

\section{DISCUSSION}

Ginsan promotes cellular cytotoxicity against a variety of tumor cells [17]. In addition, ginsan-activated killer cells have phenotypes that are distinct from IL-2-activated killer cells. Although previous studies of the effects of ginsan on spleen cells have focused on the function of effector cells, we aimed to elucidate its effects on additional aspects of lymphocyte function, such as which subsets respond to ginsan, the potential protective roles against spontaneous cell death, and influences on activation and related cytokine production.

The spleen consists of $\mathrm{T}$ and B lymphocytes, natural killer cells, macrophages, and dendritic cells. The spleen cells used in the present study were almost all lymphocytes, due to the removal of adherent cells during the preparation procedure. This was supported by flow cytometric analysis, which showed that more than $90 \%$ of the cells were $\mathrm{CD} 4^{+}$, $\mathrm{CD}^{+}$, and $\mathrm{CD} 9^{+}$cells. Although previous studies have demonstrated that cytotoxic T lymphocytes and LAK cells are generated with ginsan when synergized with IL-2, we observed increased proliferation of $\mathrm{CD} 19^{+} \mathrm{B}$ lymphocytes compared to $\mathrm{CD} 4^{+}$and $\mathrm{CD} 8^{+} \mathrm{T}$ cells. It is possible that $\mathrm{T}$ lymphocytes are converted into killer cells in the absence of significant proliferation. The specific increase of $\mathrm{CD} 19^{+}$ B lymphocytes in ginsan-activated spleen cells suggests that ginsan could be used to enhance humoral immunity [18]. However, it remains unclear which isotype of IgG may be produced by ginsan treatment and whether or not ginsan may regulate the production of antigen-specific IgG. These questions should be investigated in future studies.

Harvested spleen cells enter a state of spontaneous cell death due to the lack of growth and survival factors that are provided in vivo. In the experimental design, ginsan enhanced the viability of spleen cells in a concentrationdependent manner. Therefore, we investigated the mechanism by which ginsan enhances viability, and found that ginsan decreased the percentage of cells in late apoptosis. In addition, we found that spontaneous cell death of spleen cells and the protective effects of ginsan were closely related to the mitochondrial membrane potential.

A variety of immune responses are closely associated with the function of lymphocytes as effector cells. To mount a sufficient immune response, the lymphocytes, especially antigen-specific clones, must proliferate. We demonstrated that lymphocytes proliferated more following ginsan activation plus IL-2 treatment than after IL-2 treatment alone. Because ginsan also increased the expression of CD25, the alpha chain of the IL-2 receptor, ginsan may sensitize 
spleen cells to IL-2 via CD25 expression. In addition, ginsan treatment enhanced IL-2 production from spleen cell culture in vitro. Taken together, these data strongly suggest that ginsan induces the proliferation of lymphocytes, including clonal expansion, via multiple mechanisms. Ginsan has cytoprotective and proliferative effects on spleen cells, and selectively influences B lymphocyte proliferation. This study may help researchers to broaden the use of ginsan as an immunostimulating agent.

\section{ACKNOWLEDGEMENTS}

This research was supported by Technology Development Program for Agriculture and Forestry, Ministry for Food, Agriculture, Forestry and Fisheries, Republic of Korea.

\section{REFERENCES}

1. Shim JY, Kim MH, Kim HD, Ahn JY, Yun YS, Song JY. Protective action of the immunomodulator ginsan against carbon tetrachloride-induced liver injury via control of oxidative stress and the inflammatory response. Toxicol Appl Pharmacol. 2010; 242:318-325.

2. Kim HJ, Kim MH, Byon YY, Park JW, Jee Y, Joo HG. Radioprotective effects of an acidic polysaccharide of Panax ginseng on bone marrow cells. $J$ Vet Sci. 2007;8:39-44.

3. Shim JY, Han Y, Ahn JY, Yun YS, Song JY. Chemoprotective and adjuvant effects of immunomodulator ginsan in cyclophosphamide-treated normal and tumor bearing mice. Int $J$ Immunopathol Pharmacol. 2007;20:487-497.

4. Ahn JY, Choi IS, Shim JY, Yun EK, Yun YS, Jeong G, Song JY. The immunomodulator ginsan induces resistance to experimental sepsis by inhibiting Toll-like receptor-mediated inflammatory signals. Eur J Immunol. 2006;36:37-45.

5. Kim MH, Byon YY, Ko EJ, Song JY, Yun YS, Shin T, Joo HG. Immunomodulatory activity of ginsan, a polysaccharide of Panax ginseng, on dendritic cells. Kor J Physiol Pharmacol. 2009;13: 169-173.

6. Kim KH, Lee YS, Jung IS, Park SY, Chung HY, Lee IR, Yun YS. Acidic polysaccharide from Panax ginseng, ginsan, induces
Th1 cell and macrophage cytokines and generates LAK cells in synergy with rIL-2. Planta Med. 1998;64:110-115.

7. Han SK, Song JY, Yun YS, Yi SY. Ginsan improved Th1 immune response inhibited by gamma radiation. Arch Pharm Res. 2005;28:343-350.

8. Joo HG, Goedegebuure PS, Sadanaga N, Nagoshi M, von Bernstorff W, Eberlein TJ. Expression and function of galectin-3, a $\beta$-galactoside-binding protein in activated T lymphocytes. $J$ Leukoc Biol. 2001;69:555-564.

9. Byon YY, Kim MH, Yoo ES, Hwang KK, Jee Y, Shin T, Joo HG. Radioprotective effects of fucoidan on bone marrow cells: improvement of the cell survival and immunoreactivity. $J$ Vet Sci. 2008;9:359-365.

10. Sugrue MM, Tatton WG. Mitochondrial membrane potential in aging cells. Biol Signals Recept. 2001;10:176-188.

11. Hieronymus T, Blank N, Gruenke M, Winkler S, Haas JP, Kalden JR, Lorenz HM. CD 95-independent mechanisms of IL-2 deprivation-induced apoptosis in activated human lymphocytes. Cell Death Differ. 2000;7:538-547.

12. Letai A. Growth factor withdrawal and apoptosis: the middle game. Mol Cell. 2006;21:728-730.

13. Fleischer A, Duhamel M, Lopez-Fernandez LA, Muñoz M, Rebollo MP, Alvarez-Franco F, Rebollo A. Cascade of transcriptional induction and repression during IL-2 deprivation-induced apoptosis. Immunol Lett. 2007;112:9-29.

14. Sancho D, Gómez M, Sánchez-Madrid F. CD69 is an immunoregulatory molecule induced following activation. Trends Immunol. 2005;6:136-140.

15. Rush JS, Hodgkin PD. B cells activated via CD40 and IL-4 undergo a division burst but require continued stimulation to maintain division, survival and differentiation. Eur J Immunol. 2001;31:1150-1159.

16. Quigley M, Martinez J, Huang X, Yang Y. A critical role for direct TLR2-MyD88 signaling in CD8 T-cell clonal expansion and memory formation following vaccinia viral infection. Blood. 2009;113:2256-2264.

17. Lee YS, Chung IS, Lee IR, Kim KH, Hong WS, Yun YS. Activation of multiple effector pathways of immune system by the antineoplastic immunostimulator acidic polysaccharide ginsan isolated from Panax ginseng. Anticancer Res. 1997;17:323-331.

18. Tangye SG, Hodgkin PD. Divide and conquer: the importance of cell division in regulating B-cell responses. Immunology. 2004;112:509-520. 